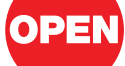

SUBJECT AREAS:

POLYMER CHEMISTRY

NANOBIOTECHNOLOGY

BIOPHYSICAL CHEMISTRY

CHEMICAL BIOLOGY

Received

7 June 2012

Accepted

30 October 2012

Published

27 November 2012

Correspondence and requests for materials should be addressed to

H.M. (hwma2008@

sinano.ac.cn)

* These authors contributed equally to this work.

\section{A proton shelter inspired by the sugar coating of acidophilic archaea}

\author{
Xiumei Wang ${ }^{1,2,3 *}$, Bei'er Lv ${ }^{1,3,4 *}$, Guixin Cai ', Long Fu', Yuanzi Wu' ${ }^{1}$ Xiang Wang ${ }^{5}$, Bin Ren ${ }^{5}$ \\ \& Hongwei $M a^{1}$
}

'Division of Nanobiomedicine, Suzhou Institute of Nano-Tech and Nano-Bionics, Chinese Academy of Sciences, Suzhou, 215123 P. R. China, ${ }^{2}$ Technical Institute of Physics and Chemistry, Chinese Academy of Sciences, Beijing, 100190, P. R. China, ${ }^{3}$ Graduate University of Chinese Academy of Sciences, Beijing, 100049, P. R. China, ${ }^{4}$ Institute of Chemistry, Chinese Academy of Sciences, Beijing 100190, China, ${ }^{5}$ Department of Chemistry, Xiamen University, Xiamen, 361005, P. R. China.

The acidophilic archaeons are a group of single-celled microorganisms that flourish in hot acid springs (usually $\mathrm{pH}<3$ ) but maintain their internal $\mathrm{pH}$ near neutral. Although there is a lack of direct evidence, the abundance of sugar modifications on the cell surface has been suggested to provide the acidophiles with protection against proton invasion. In this study, a hydroxyl $(\mathrm{OH})$-rich polymer brush layer was prepared to mimic the $\mathrm{OH}$-rich sugar coating. Using a novel $\mathrm{pH}$-sensitive dithioacetal molecule as a probe, we studied the proton-resisting property and found that a $10-\mathrm{nm}$-thick polymer layer was able to raise the $\mathrm{pH}$ from 1.0 to $>5.0$, indicating that the densely packed $\mathrm{OH}$-rich layer is a proton shelter. As strong evidence for the role of sugar coatings as proton barriers, this biomimetic study provides insight into evolutionary biology, and the results also could be expanded for the development of biocompatible anti-acid materials.

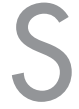

everal mechanisms have been suggested to act synergistically to maintain the $\mathrm{pH}$ homeostasis of acidophilic archaea, including the intracellular positive transmembrane potential that inhibits proton influx and antiporters that pump out excess protons ${ }^{1-4}$, with the most comprehensive evidence being reported for the extremely low proton permeability of the cell membrane ${ }^{1,3,5,6}$. The plasma membrane of acidophilic archaeons is unique in two aspects (Fig. 1). First, unlike the bilayer structure commonly found in other archaeal, bacterial or eukaryotic cell membranes, it is a monolayer composed of unique "tetraether lipids" in which two hydrophilic heads attached to the same hydrophobic tail through ether bonds and is, therefore, physiochemically more stable and less fluid ${ }^{2,6-10}$. Second, in addition to the tetraether core structure, the membrane lipids are also characterized by a substantially high content of glycolipids (as high as $>90 \%$ in some species), with one or more sugar units exposed at the outer surface of the cell ${ }^{8,9}$. This structure has been suggested to provide proton resistance because the average number of sugar units attached increases when the environmental $\mathrm{pH}$ decreases ${ }^{11}$. However, a deeper understanding of this mechanism had been hindered, mainly due to the lack of proper tools. In the present study, this biological proton shelter was studied within a novel biomimicry context by mimicking the hydroxyl $(\mathrm{OH})$ rich sugar coating with $\mathrm{OH}$-rich polymer brushes.

\section{Results}

Design of the biomimicry regime. Three tools made a detailed study of the above enigma possible: (1) a newly designed acid-probing dithioacetal molecule (Compound 1, Fig. 2a), (2) the surface-initiated polymerization (SIP) to prepare the finely tuned polymer brushes ${ }^{12}$ (Fig. $2 \mathrm{~b}$ ) and (3) the quartz crystal microbalance (QCM) that is sensitive to interfacial changes ${ }^{13-15}$ (Fig. 3a).

Compound $\mathbf{1}$ is a novel $\mathrm{pH}$-sensitive initiator of the SIP that forms self-assembled monolayers ${ }^{16}$ (SAMs) on a gold surface that is stable at neutral $\mathrm{pH}$ values (down to 5.0), whereas undergoes partial disassembly when exposed to dilute hydrochloric acid ( $\mathrm{HCl}, \mathrm{pH} 1.0$, Supplementary Fig. S2). The SAM of 1 plays two roles in this study: (1) because of its acid-sensitivity, it was used as a sensing layer that could probe local $\mathrm{pH}$ changes, and (2) because of the bromoisobutyryloxy end it contains, it was used as a layer of initiators from which the poly(oligo(ethylene glycol) methacrylate) (hereafter abbreviated as poly(OEGMA)) brushes were grafted via the SIP (Fig. 2b). The monomer OEGMA ${ }_{526}\left(\mathrm{M}_{\mathrm{n}}=526 \mathrm{~g} \mathrm{~mol}^{-1}\right)$ was used to prepare the $\mathrm{OH}$-rich brushes to mimic the OH-rich sugar coating on acidophilic archaeons, whereas $\mathrm{OEGMA}_{475}\left(\mathrm{M}_{\mathrm{n}}=475 \mathrm{~g} \mathrm{~mol}^{-1}\right)$ was used to prepare the $\mathrm{OCH}_{3}$-rich brushes as the control. 


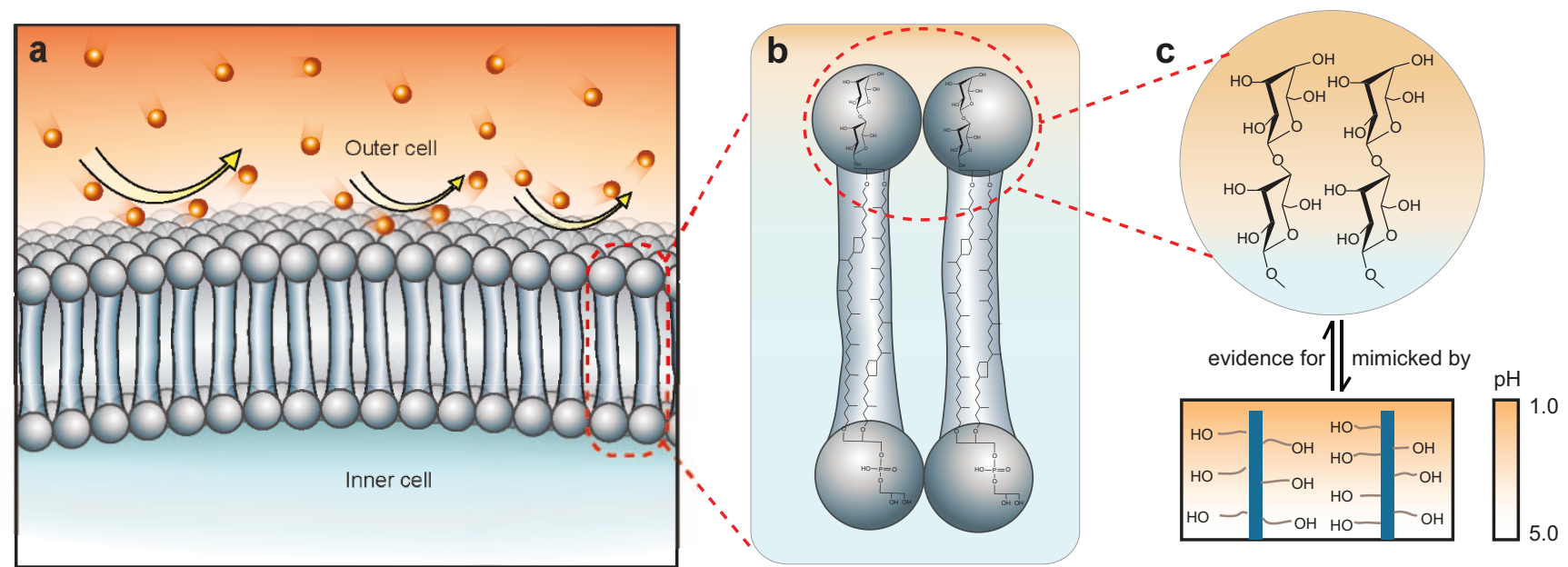

Figure $1 \mid$ Adaptation of the cell membrane of acidophilic archaea to a low $\mathbf{p H}$. (a) The single-layered cell membrane is highly resistant to proton permeation and can withstand a steep transmembrane $\mathrm{pH}$ gradient. (b) Enlarged view demonstrating the molecular structure of a tetraether lipid in which the sugar chains and phosphate group are connected to each side of two hydrocarbon chains via four ether bonds. Shown is one of the dominating sugar moieties: gulose. (c), Hydroxyl groups on the sugar moieties prevent the protons from penetrating the cell membrane, which is evidenced by the OH-rich polymer mimic.

The SAM and polymer brushes were prepared on the gold electrode of a QCM chip for QCM measurements under various $\mathrm{pH}$ solutions. QCM is an acoustic-based sensor that detects interfacial mass losses as frequency increases $(\Delta f>0)^{15,17}$. The polymer-coated chip was treated with $\mathrm{HCl}(\mathrm{pH} 1.0)$ to mimic the environmental $\mathrm{pH}$ of acidophiles (Fig. 2b). If the $\mathrm{H}^{+}$from the $\mathrm{HCl}$ reached the Au-S bonds, one would observe frequency increases due to the partial disassembly of the SAM and attached polymer chains. If the polymer layer exerted any inhibiting effect on proton permeation, the frequency response would be weakened or silenced.

Examination of the effect of the $\mathrm{OH}-$ rich polymer as a proton shelter. First, the chips grafted with poly $\left(\mathrm{OEGMA}_{475}\right)$ were challenged with $\mathrm{HCl}$. As is shown by the red line in Fig. 3a, the QCM frequency remained unresponsive to the $\mathrm{pH} 5.0 \mathrm{HCl}$ but increased significantly when exposed to the $\mathrm{pH} 1.0 \mathrm{HCl}$, indicating that the $\mathrm{H}^{+}$from $\mathrm{HCl}$ penetrated the poly $\left(\mathrm{OEGMA}{ }_{475}\right)$ layer and reached the Au-S bonds. As a control, poly(OEGMA $\left.{ }_{475}\right)$ was also grafted from the acid-treated 1 SAMs and thiol initiator $(\omega$ mercaptoundecyl bromoisobutyrate) SAMs (Supplementary Figs S5 and S6). The resulting chips showed no acid responses, confirming that the mass loss in Fig. 3a (red line) was driven by the acid-sensitivity of the 1 SAMs. The acid-induced partial loss of surface mass was also evidenced by atomic force microscopy (Supplementary Fig. S7).

The poly(OEGMA $\left.{ }_{526}\right)$-covered chips were also investigated. As shown in Fig. $3 a$ (the black line), no significant $\Delta f$ was recorded when the $\mathrm{pH}$ value dropped from 5.0 to 1.0 , indicating that the $\mathrm{H}^{+}$from $\mathrm{HCl}$ did not fully penetrate the poly $\left(\mathrm{OEGMA}_{526}\right)$ coating and that the local $\mathrm{pH}$ near the Au-S bonds was at least $>$ 5.0. This is strong evidence that the replacement of $-\mathrm{OCH}_{3}$ groups to $-\mathrm{OH}$ groups enabled the polymer coating to act as a proton shelter. Similar results were observed when OEGMA $300\left(\mathrm{M}_{\mathrm{n}}=300 \mathrm{~g} \mathrm{~mol}^{-1}\right.$, $-\mathrm{OCH}_{3}$ terminated) and $\mathrm{OEGMA}_{360}\left(\mathrm{M}_{\mathrm{n}}=360 \mathrm{~g} \mathrm{~mol}^{-1},-\mathrm{OH}\right.$ terminated) were used as another pair of $-\mathrm{OCH}_{3} /-\mathrm{OH}$-presenting monomers in the SIP (Supplementary Figs S8 and S9).

To confirm the inhibition effect of $-\mathrm{OH}$ groups on $\mathrm{H}^{+}$penetration further, we designed the following series of experiments. First, we copolymerized OEGMA 526 and OEGMA 475 at different feed ratios to tune the relative content between the $-\mathrm{OCH}_{3}$ and $-\mathrm{OH}$ ends (Supplementary Fig. S10). The result demonstrated that the $\mathrm{pH}$ response was completely silenced when the proportion of OEGMA $\mathrm{O}_{526}$ in the copolymer was as low as $10 \%$; a significant proton-resistant effect was still observed even when that ratio dropped to $0.1 \%$. Second, when the $-\mathrm{OH}$ ends in the $10 \% \mathrm{OEGMA}_{526}$-containing copolymer were converted to $-\mathrm{OCH}_{3}$ groups using $\mathrm{MeI}$, the $\mathrm{pH}$-responsiveness was regained, as expected (Supplementary Fig. S11). Cyclic voltammetry $(\mathrm{CV})$ experiments also indicated a higher electronic resistance of poly $\left(\mathrm{OEGMA}_{526}\right)$ than poly $\left(\mathrm{OEGMA}_{475}\right)$, consistent with protonblocking property ${ }^{18}$ (Supplementary Figs S12-14). All of these results support the notion that the $\mathrm{OH}$-rich polymer brushes could act as a proton shelter.

The $-\mathrm{OH}$ groups must be presented in a brush form to gain the proton-shelter function, i.e., the $-\mathrm{OH}$ groups must be spatially confined. When a poly $\left(\mathrm{OEGMA}_{475}\right)$-grafted chip was treated with a $\mathrm{pH}$ $1.0 \mathrm{HCl}$ solution containing $1 \mathrm{mM} \mathrm{OEGMA}_{526}$ monomer, a $\Delta f>0$ was observed (Supplementary Fig. S15), indicating that the free form of the $-\mathrm{OH}$ groups in solution did not suppress the $\mathrm{pH}$ response. Therefore, the surface-grafted polymer brushes were necessary for the confinement and enrichment of the - $\mathrm{OH}$ groups, a mimic to the conditions in glycolipids.

To assess further the effect in three-dimensional compartments, the proton-shelter was lifted up from the SAM surface by block copolymerization in which a "proton-conductive" layer containing exclusively poly(OEGMA $\left.{ }_{475}\right)$ was first prepared as a spacer to set the distance between the "proton shelter layer" and the SAM (Fig. 3b). The chips with this two-layer architecture were subjected to acid treatment, and a prominent proton-resisting function was observed, even when the distance increased to $80 \mathrm{~nm}$ (24 nm of dry thickness of the poly $\left(\mathrm{OEGMA}_{475}\right)$ layer corresponded to $80 \mathrm{~nm}$ of wet thickness in $\mathrm{HCl}$ ), proving the proton resistance effect of the -OH groups in three-dimensional space.

\section{Discussion}

In dramatic contrast to those in bacteria or eukaryotic cells, the majority of the lipids in the cell membrane of acidophilic archaeons are glycolipids or glycophospholipids that contain at least one sugar residue on the extracellular side (Fig. 1b). When the environmental $\mathrm{pH}$ decreased from 3.0 to 1.2 , the content of glycolipids in the plasma membrane of Thermoplasma acidophilum increased and the percentage of the lipids that contained 2-4 sugar units rose from 14\% to $35 \%$, suggesting an adaptation to low $\mathrm{pH}$ values by extending the sugar chains on the cell surface ${ }^{11}$. As a systematic investigation of the 
a<smiles>CC(C)(Br)C(=O)Oc1ccc(C(SCO)SCOC(=O)O)cc1</smiles><smiles>C=C(C)C(=O)OCCCOC</smiles><smiles>C=C(C)C(=O)OCCO</smiles>

b
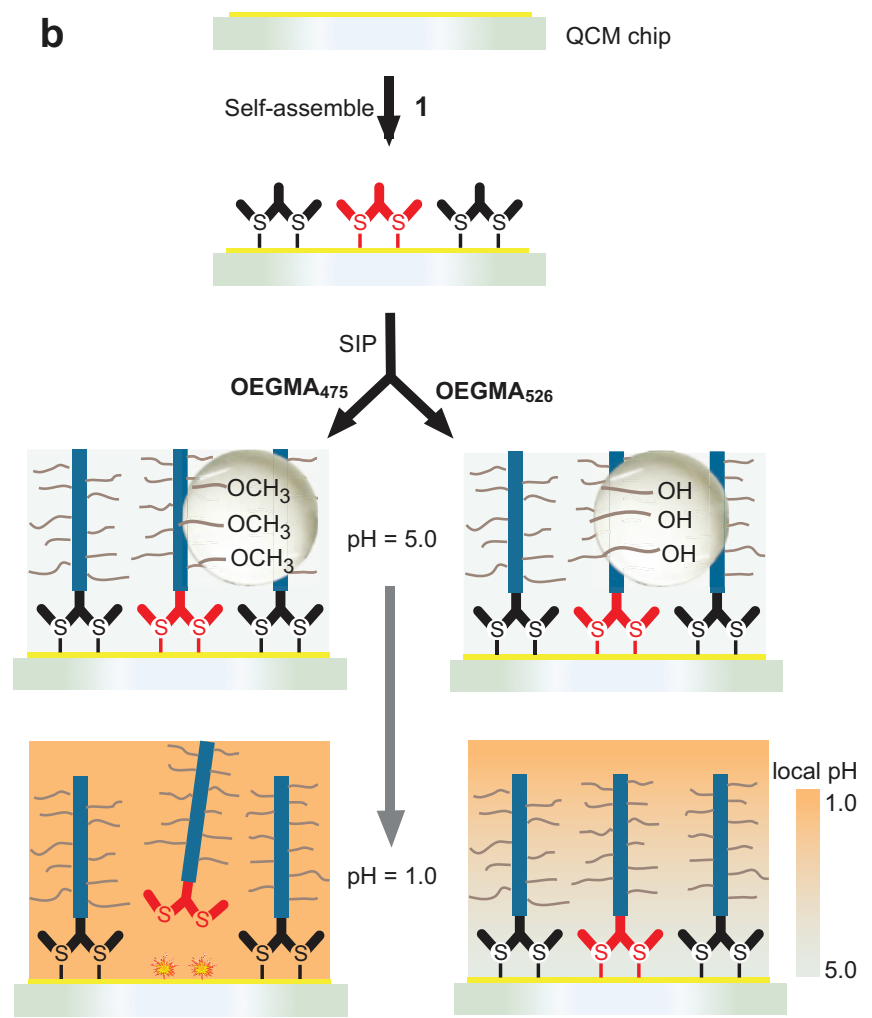

Figure $2 \mid$ Chemical structures of the initiator and monomers (a) and the construction of the three-layered system (b). (a) Chemical structure of the dithioacetal compound (Compound $\mathbf{1}$, the W-shaped initiator) and two monomers: OEGMA 475 and OEGMA 526 . (b) SAM of $\mathbf{1}$ acted as the initiator for the SIP. The polymer brushes with $-\mathrm{OCH}_{3}$ or $-\mathrm{OH}$ side chains were prepared via SIP. When the $\mathrm{pH}$ shifted from 5.0 to 1.0, proton penetration was largely blocked by the $\mathrm{OH}$-rich poly $\left(\mathrm{OEGMA}_{526}\right)$ layer, leaving a local $\mathrm{pH}$ value of at least 5.0 and resulting in no significant loss of surface mass. The acid-sensitive and -insensitive types of 1 were represented in red and black. Note that a non-existent magnifying glass was drawn to highlight the $-\mathrm{OCH}_{3}$ and $-\mathrm{OH}$ side chain ends.

effect of -OH groups on proton resistance, our study presents strong evidence for that adaptation mechanism and pinpoints the effective site as - $\mathrm{OH}$ groups. The layer remained resistant to proton permeation after 1,000-fold dilution of the $-\mathrm{OH}$ group concentration, suggesting that there a redundancy still exists with regard to the amount of $-\mathrm{OH}$ groups in our experiments. Thus it is reasonable to suppose that a layer of a few sugar units (1-2 nm in thickness) is capable of exerting moderate effects on acid defense (Fig. 1c).

The concentration of $-\mathrm{OH}$ groups inside the poly $\left(\mathrm{OEGMA}_{526}\right)$ brushes was estimated to be $0.5 \mathrm{M}$ (see Supplementary Information for the detailed calculation), which is on the similar order of magnitude with that on the cell surfaces of acidophilic archaeons, thus justifying our simulation ${ }^{19}$.
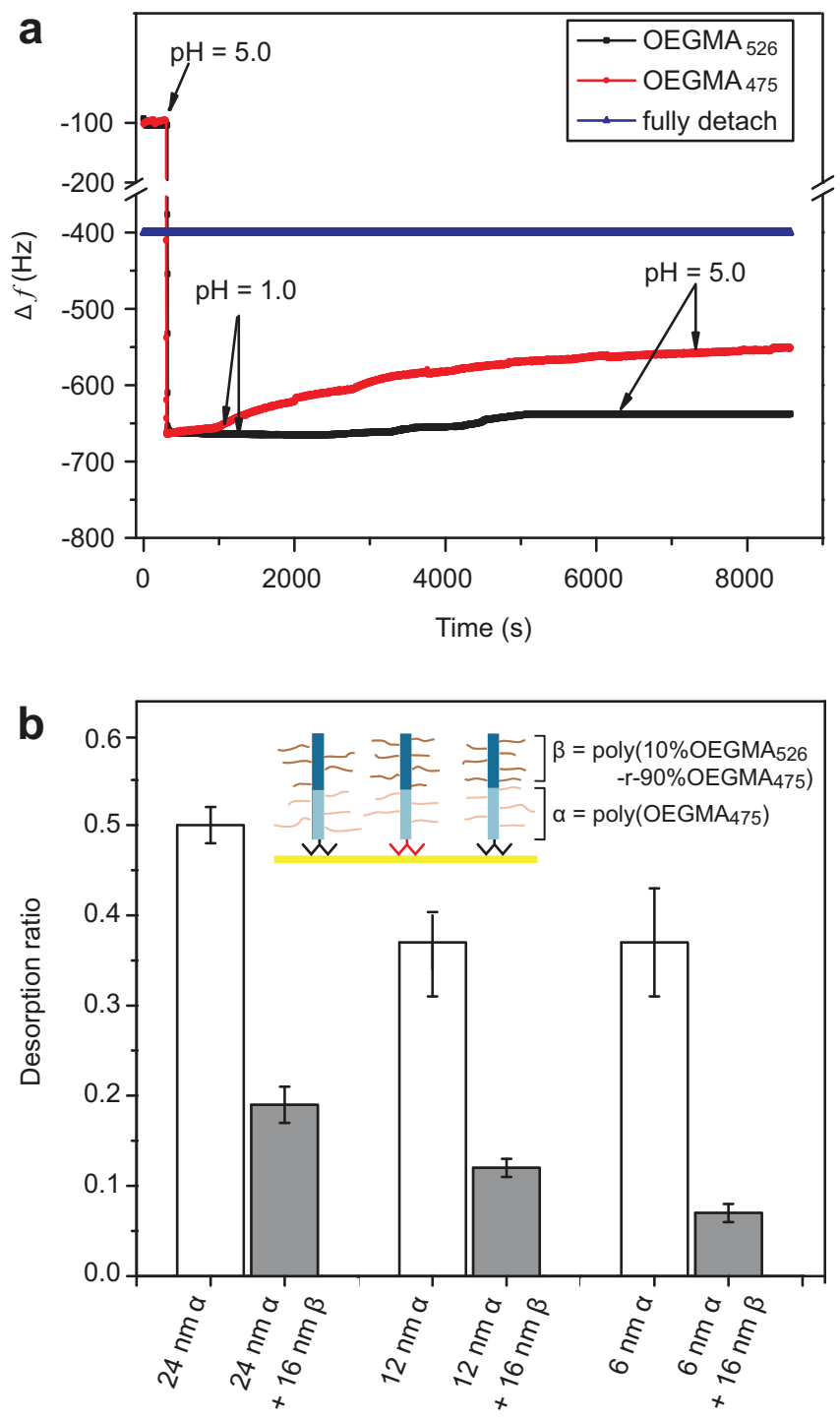

Figure 3 Proton-resisting effect of $\mathrm{OH}-$ rich poly(OEGMA $\left.{ }_{526}\right)$ brushes. (a) Different responses to acid stimulation of poly(OEGMA $\left.\mathrm{O}_{526}\right)$ - and poly $\left(\mathrm{OEGMA}_{475}\right)$-coated chips, as monitored by QCM in real time. When the $\mathrm{HCl}$ ( $\mathrm{pH}$ 5.0) was introduced, the frequency decreased due to the switch from the gaseous to liquid phases, reaching a baseline for both chips. When the $\mathrm{pH}$ changed to 1.0 , the frequency of the poly $\left(\mathrm{OEGMA}_{475}\right)$-grafted chip (10.6 nm thick polymer layer, red line) increased significantly, whereas the poly $\left(\mathrm{OEGMA}_{526}\right)$-grafted $(9.2 \mathrm{~nm})$ chip showed no response $(<20 \mathrm{~Hz}$ for over 1 hour, black line). The blue line indicates the frequency level corresponding to the complete loss of the surface mass. (b) When a poly $\left(\mathrm{OEGMA}_{475}\right)$ layer $(\alpha)$ was covered with a proton shelter copolymer layer $(\beta)$ (the gray bars), the acid-responsiveness (measured as the desorption ratio: ratio of the detached mass to the whole mass) was significantly inhibited compared with those without the proton shelter layer (the white bars). The bottom axis label shows the dry thickness of each layer.

Our study proves the strong proton-resistance of surface confined $-\mathrm{OH}$ groups and also paves the way for the investigation of the underlying mechanism. The proton-resistance properties of other groups, such as $-\mathrm{NH}_{2}$ and epoxy groups, could be studied by changing the monomers, the direction of our ongoing experiments. The results, combined with a theoretical analysis, are expected to reveal the mechanisms.

The bioinspired poly $\left(\mathrm{OEGMA}_{526}\right)$ membrane possesses a strong proton-sheltering effect that has been quantitatively defined as 
raising the $\mathrm{pH}$ from 1.0 to $>$ 5.0. Therefore, our biomimetic study may be expanded for the development of biocompatible anti-acid strategies, such as tooth protection and drug-carriers that withstand gastric acid digestion ${ }^{20}$. Our conclusion also provides information for the design of novel paints that offer protection to vehicles, buildings and infrastructures against acid rain corrosion, an area for which realistic solutions are still lacking. Furthermore, as the first organosulfur compound that has been found to form an acid-sensitive Au-S bond, compound 1 could be used to study the nature of $\mathrm{Au}-\mathrm{S}$ bonds.

\section{Methods}

2-Bromo-2-methyl-propionic acid 4-[bis-(11-hydroxy-undecylsulfanyl)-methyl] phenyl ester (1). The dithioacetal initiator (1) was synthesized using the following procedure:<smiles>O=Cc1ccc(O)cc1</smiles>

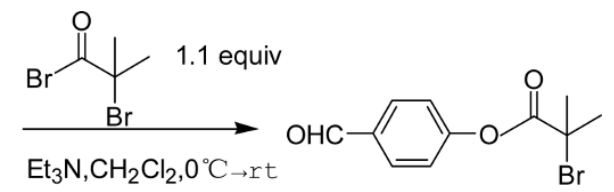

(1) Synthesis of 4-formylphenyl -2-bromo-2-methylpropanoate ${ }^{21}$ :

Hydroxybenzaldehyde ( $0.61 \mathrm{~g}, 5 \mathrm{mmol})$, triethylamine $(0.75 \mathrm{~mL}, 1.033 \mathrm{mmol})$, and dry dichloromethane $(25 \mathrm{~mL})$ were added to a $50-\mathrm{mL}$ round-bottom flask with a stir bar. The mixture was cooled to $0^{\circ} \mathrm{C}$, followed by the dropwise addition of ice-cold bromoisobutyryl bromide $(0.67 \mathrm{~mL}, 5.39 \mathrm{mmol})$. After stirring at $0^{\circ} \mathrm{C}$ for $1 \mathrm{~h}$, the reaction was continued for another $12-16 \mathrm{~h}$ at room temperature. Water $(20 \mathrm{~mL})$ and dichloromethane $(10 \mathrm{~mL})$ were added to the mixture for a two-phase extraction. The aqueous phase was further extracted with dichloromethane $(2 \times 30 \mathrm{~mL})$, and the organic phase was concentrated by rotary evaporation to remove the dichloromethane. The resulting crude extract was dissolved in dichloromethane $(40 \mathrm{~mL})$, washed with a saturated sodium bicarbonate solution $(3 \times 40 \mathrm{~mL})$, and dried over $\mathrm{MgSO}_{4}$. The removal of the dichloromethane resulted in a yellowish oil, which was passed through a column (silica gel, neutral, with petroleum ether:ethyl acetate $=$ 20:1) and then vacuum dried overnight. The final product (4-formylphenyl -2bromo-2-methylpropanoate) was a white solid, obtained in high purity and with a high yield $\left(0.2168 \mathrm{~g}, 80 \%\right.$ yield). ${ }^{1} \mathrm{H}$ NMR $\left(400 \mathrm{MHz}, \mathrm{CDCl}_{3}\right): \delta 10.013 \mathrm{ppm}(\mathrm{s}, 1 \mathrm{H})$, $7.852(\mathrm{~d}, J=8.8,2 \mathrm{H}), 7.325(\mathrm{~d}, J=8.8,2 \mathrm{H}), 2.082(\mathrm{~s}, 6 \mathrm{H}) .{ }^{13} \mathrm{C} \mathrm{NMR}(400 \mathrm{MHz}$, CDCl3): $190.775,169.598,155.371,134.309,131.243,121.907,77.312,76.995,76.671$, 54.935, 30.481.GC-MS: 271.

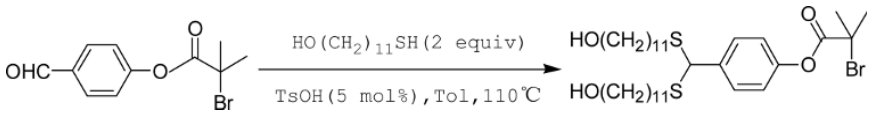

(2) Synthesis of dithioacetal initiator ${ }^{22}:$ Mercaptoundecanol ( $\left.0.48 \mathrm{~g}, 2 \mathrm{mmol}\right): 4-$ formylphenyl -2-bromo-2-methylpropanoate $(0.271 \mathrm{~g}, 1 \mathrm{mmol})$ and toluene $(10 \mathrm{~mL})$ were added to a $50 \mathrm{~mL}$ round-bottom flask with a stir bar. The mixture was refluxed to $110^{\circ} \mathrm{C}$, followed by the addition of p-toluenesulfonic acid $(0.009 \mathrm{~mL}$, $0.05 \mathrm{mmol}$ ). After stirring at $110^{\circ} \mathrm{C}$ for $3 \mathrm{~h}$, the reaction was stopped by the addition of triethylamine $(3 \mathrm{~mL})$. The mixture was concentrated by rotary evaporation to remove the toluene. The removal of the toluene resulted in an orange oil, which was passed through a column (silica gel, neutral, with petroleum ether: ethyl acetate $=2: 1$ with $2 \%$ triethylamine as eluent) and then vacuum dried overnight. The final product was a white solid, obtained in high purity and with a high yield (1.4040 g, 93.1\% yield). ${ }^{1} \mathrm{H}$ NMR $\left(400 \mathrm{MHz}, \mathrm{CDCl}_{3}\right): \delta 7.493 \mathrm{ppm}(\mathrm{d}, J=6.4,2 \mathrm{H}), 7.111(\mathrm{~d}, J=8.8$, $2 \mathrm{H}), 4.886(\mathrm{~s}, 6 \mathrm{H}), 3.642(\mathrm{t}, J=13.2,4 \mathrm{H}), 2.542(\mathrm{~m}, J=43.6,4 \mathrm{H}), 2.073(\mathrm{~s}, 6 \mathrm{H}), 1.554$ $(\mathrm{m}, J=27.6,10 \mathrm{H}), 1.322(\mathrm{~m}, J=39.6,26 \mathrm{H}) .{ }^{13} \mathrm{C}$ NMR $(400 \mathrm{MHz}, \mathrm{CDCl} 3): 169.742$, $149.711,138.303,128.540,120.665,77.317,76.994,76.675,62.273,55.052,52.155$, $32.359,31.912,30.257,29.376,29.301,29.215,29.168,28.858,28.795,28.542,25.489$. HRMS (ESI): $\mathrm{m} / \mathrm{z}=685.2739\left([\mathrm{M}+\mathrm{Na}]^{+}\right.$, calculated $\left.\mathrm{m} / \mathrm{z}=685.2759\right)$.

SAMs. The QCM chips were incubated in $1 \mathrm{mM}$ ethanol solution of 1 for 18 hours. The reaction was executed at ambient temperature, under nitrogen atmosphere protection and protected from light.

SIP. The SIP of OEGMA from the SAMs of $\mathbf{1}$ as the initiators was performed as reported previously ${ }^{15}$ using bipyridine as a ligand and water: ethanol $=1: 1$ as a solvent, with a molar ratio of OEGMA/ $\mathrm{CuBr}_{2} /$ bipyridine $/ \mathrm{CuBr} /=400 / 1 / 30 / 10$ (i.e., $10 / 0.025 / 0.75 / 0.25 \mathrm{mM}$ ). The reaction was terminated by MilliQ-water ( $\mathrm{pH} 6.2$ ), and the chips were then rinsed thoroughly with MilliQ-water and ethanol to remove any salt particles and dried under a nitrogen flow. The dry thicknesses of the surfacetethered polymer brushes were determined by Ellipsometry.

QCM measurements. All of the QCM measurements were conducted with a relative humidity controlled below $25 \%$. The operation temperature was set at $25^{\circ} \mathrm{C}$. The chips (AT cut, $5 \mathrm{MHz}$; HZDW, Hangzhou, China) were placed in a home-built QCM with control software purchased from Resonant Probes GmbH (Goslar, Germany). For the liquid-phase measurements, the QCM was operated in a flow-through mode at a speed of $80 \mathrm{~mL} \mathrm{~min}^{-1}$. Milli-Q water $(\mathrm{pH}=6.2)$ with a resistivity of $18.2 \mathrm{M} \Omega$ $\mathrm{cm}^{-1}$ was used for the solution preparation.

AFM. The AFM images of the samples in their dry state were taken in the tapping mode (Digital Instruments, Santa Barbara). The polymer-coated QCM chips were imaged before and after washing with a dilute acid solution.

Ellipsometry. The dry film thickness was measured using an M-2000V spectroscopic ellipsometer (J. A. Woollam Co., Inc.) at angles of $65^{\circ}, 70^{\circ}$ and $75^{\circ}$ and wavelengths from $400 \mathrm{~nm}$ to $800 \mathrm{~nm}$. The ellipsometric data were fitted for thickness using materialspecific models (Cauchy layer model) from a vendor-supplied software, with fixed ( $A_{n}$, $\left.B_{n}\right)$ values $(1.46,0.01)$. Each datum was an average of three measurements.

1. Baker-Austin, C. \& Dopson, M. Life in acid: $\mathrm{pH}$ homeostasis in acidophiles. Trends Microbiol. 15, 165-171 (2007).

2. van de Vossenberg, J. L. C. M., Driessen, A. J. M. \& Konings, W. N. The essence of being extremophilic: the role of the unique archaeal membrane lipids. Extremophiles 2, 163-170 (1998).

3. Konings, W., Albers, S.-V., Koning, S. \& Driessen, A. The cell membrane plays a crucial role in survival of bacteria and archaea in extreme environments. Antonie van Leeuwenhoek 81, 61-72 (2002).

4. Auernik, K. S., Cooper, C. R. \& Kelly, R. M. Life in hot acid: pathway analyses in extremely thermoacidophilic archaea. Curr. Opin. Biotechnol. 19, 445-453 (2008).

5. Elferink, M. G. L., de Wit, J. G., Driessen, A. J. M. \& Konings, W. N. Stability and proton-permeability of liposomes composed of archaeal tetraether lipids. Biochim. Biophys. Acta, Biomembr. 1193, 247-254 (1994).

6. Hanford, M. \& Peeples, T. Archaeal tetraether lipids. Appl. Biochem. Biotechnol. 97, 45-62 (2002)

7. Albers, S. V., Szabo, Z. \& Driessen, A. J. Protein secretion in the Archaea: multiple paths towards a unique cell surface. Nat. Rev. Microbiol. 4, 537-547 (2006).

8. Chong, P. L. Archaebacterial bipolar tetraether lipids: Physico-chemical and membrane properties. Chem. Phys. Lipids 163, 253-265 (2010).

9. De Rosa, M., Gambacorta, A. \& Nicolaus, B. A New type of cell membrane, in thermophilic archaebacteria, based on bipolar ether lipids. J. Membr. Sci. 16, 287-294 (1983).

10. Mathai, J. C., Sprott, G. D. \& Zeidel, M. L. Molecular mechanisms of water and solute transport across archaebacterial lipid membranes. J. Biol. Chem. 276, 27266-27271 (2001).

11. Shimada, H., Nemoto, N., Shida, Y., Oshima, T. \& Yamagishi, A. Effects of $\mathrm{pH}$ and temperature on the composition of polar lipids in Thermoplasma acidophilum HO-62. J. Bacteriol. 190, 5404-5411 (2008).

12. Ma, H., Wells, M., Beebe, T. P. \& Chilkoti, A. Surface-initiated atom transfer radical polymerization of oligo(ethylene glycol) methyl methacrylate from a mixed self-assembled monolayer on gold. Adv. Funct. Mater. 16, 640-648 (2006).

13. Ward, M. D. \& Buttry, D. A. In situ interfacial mass detection with piezoelectric transducers. Science 249, 1000-1007 (1990).

14. Zhang, Y., Du, B., Chen, X. \& Ma, H. Convergence of dissipation and impedance analysis of quartz crystal microbalance studies. Anal. Chem. 81, 642-648 (2009).

15. Zhang, Y., He, J. a., Zhu, Y., Chen, H. \& Ma, H. Directly observed Au-S bond breakage due to swelling of the anchored polyelectrolyte. Chem. Commun. 47, 1190-1192 (2011).

16. Love, J. C., Estroff, L. A., Kriebel, J. K., Nuzzo, R. G. \& Whitesides, G. M. Selfassembled monolayers of thiolates on metals as a form of nanotechnology. Chem. Rev. 105, 1103-1170 (2005).

17. Fu, L., Chen, Y. \& Ma, H. Solidified liquid layer model expands the application fields of quartz crystal microbalance. Macromol. Rapid Commun. 33, 735-741 (2012).

18. Zhou, F. et al. Polyelectrolyte brush amplified electroactuation of microcantilevers. Nano Letters 8(2), 725-730 (2008).

19. Alberts, B. et al. in Molecular Biology of The Cell Ch. 10, Garland Science, New York, 617-629 (2008)

20. Patel, G. B. \& Sprott, G. D. Archaeobacterial ether lipid liposomes (archaeosomes) as novel vaccine and drug delivery systems. Crit. Rev. Biotech. 19, 317-357 (1999).

21. Wiggins, K. M. et al. Mechanical reconfiguration of stereoisomers. J. Am. Chem. Soc. 132, 3256-3257 (2010)

22. Wu, Y.-C. \& Zhu, J. Hafnium trifluoromethanesulfonate (hafnium triflate) as a highly efficient catalyst for chemoselective thioacetalization and transthioacetalization of carbonyl compounds. J. Org. Chem. 73, 9522-9524 (2008).

\section{Acknowledgments}

This work was supported by the CAS/SAFEA International Partnership Program for Creative Research Teams, Special Foundation of President of CAS, NSFC Grant (21074148, 21174161), and National Basic Research Program of China (2009CB320300). The authors 
thank Dr. J. Y. Zhang for CV test and the support of Public Center for Characterization and Test, SINANO, CAS.

\section{Author contributions}

X.W. and G.C. carried out organic synthesis, SIP and QCM measurements. B.L. carried out SIP and was involved in CV tests. Y.W., X.W. and B.R. conducted the STM study. L.F. and G.C. participated in discussions and interpretations of the experiments. X.W., B.L. and H. M. designed this study and wrote the paper.

\section{Additional information}

Supplementary information accompanies this paper at www.nature.com/scientificreports Competing financial interests: The authors declare no competing financial interests License: This work is licensed under a Creative Commons

Attribution-NonCommercial-NoDerivs 3.0 Unported License. To view a copy of this license, visit http://creativecommons.org/licenses/by-nc-nd/3.0/

How to cite this article: Wang, X. et al. A proton shelter inspired by the sugar coating of acidophilic archaea. Sci. Rep. 2, 892; DOI:10.1038/srep00892 (2012). 